See Article page 1664.

\section{Commentary: Custom-printed Y stent in the management of tracheoesophageal fistula following esophagectomy: A new weapon in a difficult fight?}

\author{
Christopher R. Morse, MD
}

Tracheoesophageal fistula following esophagectomy is a dreaded and highly morbid complication. There is an intimate relationship between the membranous wall of the airway and the proximal esophagus. With this anatomic relationship, the potential for developing a tracheoesophageal fistula after esophagectomy is high, particularly in the setting of anastomotic leak. Traditionally requiring an open operation to manage, in this issue of the Journal, Huang and colleagues ${ }^{1}$ describe an innovative technique in which a 3-dimensional (3D)-printed metallic, covered stent is used to manage the defect.

The use of stents in the management of tracheoesophageal fistula is often complicated by an inability to have an esophageal stent seal completely, poorly controlling aspiration, and the difficulty with a non-custom Y-shaped airway stent not fitting a particular patient's geometry or injury. With advancements in imaging and 3D printing, patientspecific metallic-covered airway stents can be designed and generated to fit the anatomic needs of a patient.

The study of Huang and colleagues certainly adds to our ability to treat a difficult problem, but there are several limitations. This technology is not available to all facilities treating tracheoesophageal fistula following esophagectomy and requires considerable engineering expertise and investment. Furthermore, a large percentage of patients

\footnotetext{
From the Division of Thoracic Surgery, Department of Surgery, Massachusetts General Hospital, Boston, Mass.

Disclosures: The author reported no conflicts of interest.

The Journal policy requires editors and reviewers to disclose conflicts of interest and to decline handling or reviewing manuscripts for which they may have a conflict of interest. The editors and reviewers of this article have no conflicts of interest.

Received for publication April 1, 2020; revisions received April 1, 2020; accepted for publication April 1, 2020; available ahead of print April 18, 2020.

Address for reprints: Christopher R. Morse, MD, Division of Thoracic Surgery, Department of Surgery, Massachusetts General Hospital, 55 Fruit St, Boston, MA 02114 (E-mail: crmorse@partners.org).

J Thorac Cardiovasc Surg 2021;161:1673

$0022-5223 / \$ 36.00$

Copyright (C) 2020 by The American Association for Thoracic Surgery

https://doi.org/10.1016/j.jtcvs.2020.04.019
}

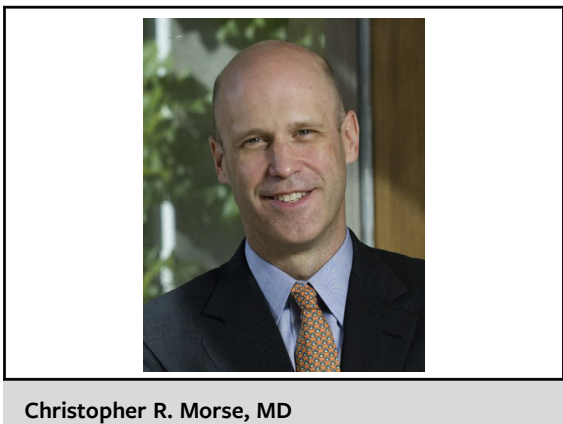

Christopher R. Morse, MD

$$
\begin{aligned}
& \text { CENTRAL MESSAGE } \\
& \text { Tracheoesophageal fistula } \\
& \text { following esophagectomy can be } \\
& \text { a devastating complication. Using } \\
& \text { 3D printing technology, there is } \\
& \text { an additional intervention that } \\
& \text { may help a select group of } \\
& \text { patients. }
\end{aligned}
$$

with a tracheoesophageal fistula following esophagectomy present with profound respiratory insufficiency, mediastinal and pleural sepsis, and possible multiorgan dysfunction. These patients should not be managed with stent placement and require a larger, more definitive procedure.

However, when applied to the appropriate patient, the option of $3 \mathrm{D}$ printing a custom covered metallic stent to manage ongoing aspiration in the setting of a tracheoesophageal fistula vastly increases our ability to treat these patients without the morbidity of a large, open operation. As this technology becomes more universal, this expertise will be available at more centers, but this is not a "one size fits all." It remains imperative patients are carefully selected for stent placement rather than a definitive diversion or open repair.

\section{Reference}

1. Huang W, Shan Q, Wu Z, Li H, Zhou M, Ding X, et al. Retrievable covered metallic segmented Y airway stent for gastrorespiratory fistula of carina or main bronchi. J Thorac Cardiovasc Surg. 2021;161:1664-71.e2. 